\title{
Suspected appendicitis during pregnancy: prevalence and management at prince Hashem Ben AL-Hussein Hospital (Zarqa/Jordan)
}

Hasan Al- Dahamsheh

Departments of Obstetric \& Gynecology Prince Hashem Ben Al-Hussein Hospital/Royal Medical Services, Zarqa, Jordan

\begin{abstract}
To evaluate the clinical picture and outcome of suspected appendicitis in pregnant women. Retrospective analytic study of 28 appendectomies performed during pregnancy for suspected appendicitis in our hospital at period April 2004 to September 2006. All files and medical records of these patients were analyzed and studied. Those including variables (demographic, clinical, laboratory and surgical outcomes data) were collected retrospectively. Prevalence of appendicitis was calculated from the total number of deliveries and abortions that occurred during this period. Numbers of correct and wrong diagnosis were reported and comparison of perinatal outcome, maternal morbidity and different variables in negative and positive laparotomies performed.
\end{abstract}

The prevalence of suspected appendicitis in pregnancy is $0.29 \%$. Incidences of negative laparotomies were $36 \%$. The most diagnostic findings for acute appendicitis were history of periumbilical pain, anorexia and Rt iliac fossa findings. Half of wrong diagnosis were related to premature labor pain or abortion.

The prevalence of suspected appendicitis during pregnancy in our environment during this period was higher than the reported incidence and rate of wrong diagnosis still high. Good clinical assessment with adjunct ultrasonic examination could reduce the incidence of negative laparotomies or prevent late complication. Delay in operation leading to higher rate of maternal morbidity and adversely affect the obstetric outcome.

Key word: Acute appendicitis, negative laparotomy, pregnancy, Suspected.

\section{Indroduction}

Acute appendicitis is the most common nonobstetrical operative procedure during pregnancy with an incidence of 1 in 500-10000 pregnancies. ${ }^{1,2,3,4}$ It represents a dilemma because its symptoms resemble the usual normal symptoms of pregnancy, and laparotomy in pregnancy has a risk of miscarriage and preterm labor. Incorrect diagnosis has been reported Correspondence: Hasan Al- Dahamsheh E-mail: dhamshdr66@yahoo.com in $25 \%$ to $50 \%$ of patients ${ }^{5,6,7}$, and rates of fetal loss and early delivery in negative laparotomy were $4 \%$ and $10 \%$ respectively. ${ }^{7}$ Conversely, the delay in diagnosis and surgical intervention carries a risk of appendicular perforation, which increase significantly the risk to the mother and the fetus ${ }^{7,8}$. The risk of perforation increased during the later stages of pregnancy, with $8.7 \%$ of all perforations occurring during the first trimester, $12.5 \%$ in the second trimester, and $26.1 \%$ in the third trimester. ${ }^{9}$ 
Hasan Al- Dahamsheh, Suspected appendicitis during pregnancy: prevalence and management

In our environment the true rate of acute appendicitis in pregnant women is not known and its management is unclear. The purpose of our study is to estimate this prevalence, to analyze the clinical presentation and asses the early surgical intervention in relationship to maternal health and fetal outcome.

\section{Materials and methods}

This is a retrospective study of 28 cases of suspected appendicitis in pregnancy from April 2004 to September 2006 at Prince Hashem Hospital(Zarqa, Jordan).

Twenty eight cases of appendectomies during pregnancy were identified and included in the study. All files and medical records of these patients were analyzed and studied. Demographic, clinical, laboratory and surgical outcomes data were collected retrospectively. And the primary outcomes variable was the histopathology report( normal or inflamed appendix). Prevalence were calculated from the total number of deliveries and abortions that occurred during this period. Demographic variables included age, body mass index (BMI) and parity. Clinical data included abdominal pain(epigastric, Rt iliac fossa, periumbilical or Rt upper quadrant),nausea, vomiting , anorexia, fever, tachycardia, abdominal tenderness ( Rt iliac fossa or Rt upper quadrant),positive or negative rebound (Rt iliac fossa or Rt upper quadrant), rigidity and palpable mass . Laboratory data included WBC count and ultrasonic findings . Surgical outcomes data included maternal morbidity and fetal outcome. Maternal morbidity was assessed by recurrent hospital admissions, duration of hospital stay, postoperative fever, presence of labor pain and wound infection. Fetal outcome was assessed from the reported abortion or prematurity.

\section{Statistical methods}

Differences in baseline characteristics were evaluated using fisher's exact test (2-tailed) for categorical variables and the wilcoxon rank sum test for continuous or ordinal data. Continuous data were presented as means with standard deviations (Mean \pm SD). Significance was determined at the $\mathrm{p}<0.05$ level (2tailed). Using a set of demographical, clinical and laboratory outcomes data as independent variables and suspected appendicitis as a dependent variable and the primary outcomes defined as histopathology confirmed appendicitis.

Each factor found to be significant on univariate analysis were included in the multivariate model. Multivariate analysis was performed with binary logistic regression. Statistical analysis was performed using the Statistical Package for the Social Sciences (SPSS) for Windows version 17.0 (SPSS Inc, Chicago, Illinois).

\section{Results}

During the period of the study there were 9783 deliveries and abortions. Twenty eight $(0.29 \%)$ cases were provisionally diagnosed and admitted as having acute appendicitis with pregnancy. The frequency of histopathology confirmed appendicitis to all deliveries and abortions was $0.18 \%$.

Table 1 summarizes the demographic data of women, the frequency of the symptoms and signs of appendicitis, ultrasonic and laboratory findings. The mean gestational 
Journal of College of Medical Sciences-Nepal, 2012, Vol-8, No-1

age at presentation was $23.6 \pm 8.9$ weeks with the higher frequently in third trimester (46\%) but not significant in relation to other trimesters.

Table 1. Demographic data and presentation of pregnant women with suspected appendicitis

Total number of patients

28

Age(year) (mean $\pm \mathrm{SD})$

$26.7 \pm 5.8$

Parity $($ mean \pm SD)

$2.8 \pm 2.1$

Body mass index $(\mathrm{kg} / \mathrm{m} 2)($ mean $\pm \mathrm{SD})$

Gestational age (week) (mean \pm SD)

$23.6 \pm 8.9$

\section{Symptoms (N) (\%)}

Epigastric Pain

Periumbilical Pain

Rt iliac Fossa Pain

Rt upper quadrant Pain

Nausea

Vomiting

Anorexia

\section{Signs (N) (\%)}

Fever

Tachycardia

$16(57.1 \%)$

Tenderness $25(89.3 \%)$ $20(71.4 \%)$
Rebound tenderness

Positive

$17(60.7 \%)$

Equivocal $7(25 \%)$

Muscular rigidity

Appendicular mass

Laboratory result

Negative ultrasonic findings

Normal histopathological findings

Leukocytosis

$17(60.7 \%)$

The under study factors were compared between the two groups (women with confirmed appendicitis versus women with normal appendix ) table 2 . Nine factors found to be of significant difference within both groups: periumbilical abdominal pain ( $\mathrm{p}=.04$ ), vomiting $(\mathrm{p}=.02)$, anorexia $(\mathrm{p}=.01)$, tachycardia $(\mathrm{p}=.01)$, Rt iliac $8(28.6 \%)$ fossa tenderness $(\mathrm{p}=.008)$, negative rebound tenderness $(\mathrm{p}=.04)$, positive rebound tenderness $(\mathrm{p}=.01)$, leukocytosis $(\mathrm{p}=.04)$ and positive ultrasonic findings $(\mathrm{p}=.02)$. But on multivariate analysis five factors of nine factors mention above remain significant: anorexia $(p=.01)$, tachycardia $(p=.01), R t$ iliac fossa tenderness $(\mathrm{p}<.001)$, negative rebound tenderness $(\mathrm{p}=.02)$ and positive rebound tenderness ( $\mathrm{p}<.001$ ) table 2.The other factors (age, parity, BMI, gestational age, fever, nausea, vomiting, rigidity and absence of appendicular lump) were not significant

\section{table 2.}


Hasan Al- Dahamsheh, Suspected appendicitis during pregnancy: prevalence and management

Table 2 Comparison between pregnant with confirmed appendicitis and pregnant with normal appendix

\begin{tabular}{|c|c|c|c|c|}
\hline & $\begin{array}{c}\text { Women with } \\
\text { confirmed appendicitis } \\
\mathrm{N}=19\end{array}$ & $\begin{array}{c}\text { Women with } \\
\text { normal appendix } \\
\mathrm{N}=9\end{array}$ & $\begin{array}{c}\text { Significance of } \\
\text { differences } \\
\text { (p value) }\end{array}$ & $\begin{array}{c}\text { Logistic } \\
\text { Regression } \\
\text { (p value) }\end{array}$ \\
\hline Age & $24 \pm 4.9$ & $27.9 \pm 6$ & .09 & .10 \\
\hline Parity & $1.8 \pm 1.5$ & $3.2 \pm 2.3$ & .08 & .12 \\
\hline BMI & $23.4 \pm 3.3$ & $25.9 \pm 4.2$ & .11 & .13 \\
\hline Gestational age & $21.7 \pm 9.4$ & $24.5 \pm 8.7$ & .46 & .42 \\
\hline \multicolumn{5}{|l|}{ Abdominal pain } \\
\hline Epigastric & $4(44.4 \%)$ & $4(21.1 \%)$ & .89 & .06 \\
\hline Periumbilical & $6(31.6 \%)$ & $3(33.3 \%)$ & .04 & .03 \\
\hline Rt iliac Fossa & $7(36.8 \%)$ & $1(11.1 \%)$ & .13 & .01 \\
\hline Rt upper quadrant & $2(10.5 \%)$ & $1(11.1 \%)$ & .11 & .62 \\
\hline Nausea & $17(89.5)$ & $8(88.9 \%)$ & .96 & .76 \\
\hline Vomiting & $16(84.2 \%)$ & $5(55.6 \%)$ & .02 & .77 \\
\hline Anorexia & $14(73.7)$ & $2(22.2 \%)$ & .01 & .01 \\
\hline Fever & $12(63.2 \%)$ & $5(55.6 \%)$ & .70 & .83 \\
\hline Tachycardia & $14(73.3 \%)$ & $2(22.2 \%)$ & .01 & .01 \\
\hline \multicolumn{5}{|l|}{ Tenderness } \\
\hline Rt iliac Fossa & $16(84.2 \%)$ & $2(22.2 \%)$ & .008 & $<.001$ \\
\hline Between Rt iliac Fossa and Rt & t UQ $3(15.8 \%)$ & $2(22 \%)$ & .11 & .001 \\
\hline \multicolumn{5}{|l|}{ Rebound tenderness } \\
\hline Negative & $1(5.3 \%)$ & $6(66.7 \%)$ & .04 & .02 \\
\hline Positive & $15(78.9 \%)$ & $2(22.2 \%)$ & .01 & .001 \\
\hline Equivocal & $3(15.8 \%)$ & $1(11.1 \%)$ & .08 & .60 \\
\hline Muscular rigidity & $6(85.7 \%)$ & $1(11.1 \%)$ & .24 & .24 \\
\hline Absence of appendicular lump & $17(89.5 \%)$ & $9(100 \%)$ & .31 & .31 \\
\hline Positive ultrasonic findings & $15(78.9 \%)$ & $3(33.3 \%)$ & .02 & .02 \\
\hline Leukocytosis & $14(73.3 \%)$ & $3(33.3 \%)$ & .04 & .19 \\
\hline
\end{tabular}


Journal of College of Medical Sciences-Nepal, 2012, Vol-8, No-1

The leukocyte count was raised in the $14(73 \%)$ patients with confirmed appendix. However, the sensitivity and specificity of leukocytosis finding for diagnosis of appendicitis was $83 \%$ and $47 \%$ respectively figure 1 .

Figure 1.Sensitivity and specificity of leukocytosis in prediction of acute appendicitis in pregnant woman

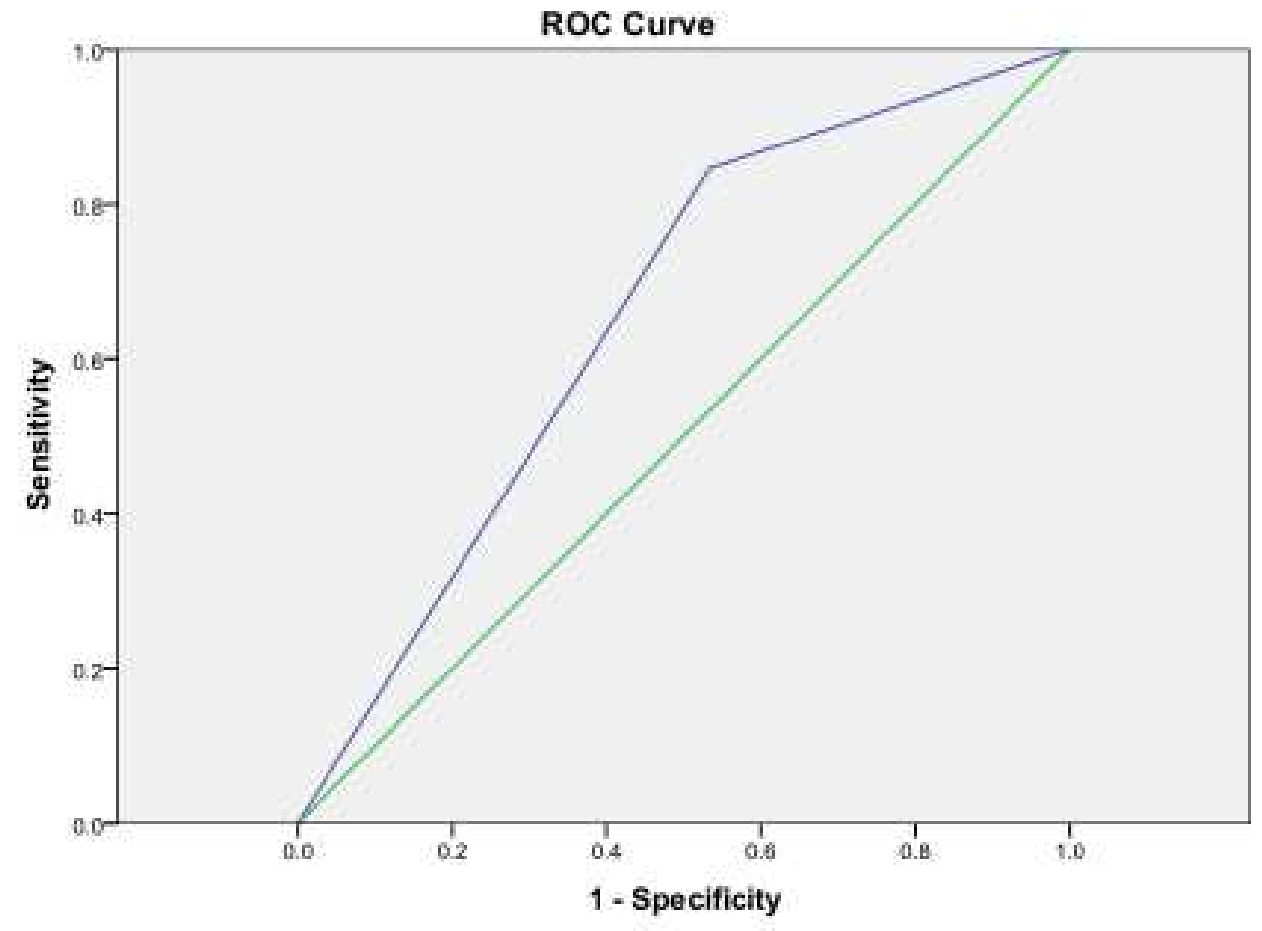

Diagonal segments are produced by ties.

Also we found that the total diagnostic accuracy of ultrasound was (75\%) figure 2.

Figure 2.Sensitivity and specificity of ultrasonic findings in prediction of acute appendicitis in pregnant woman

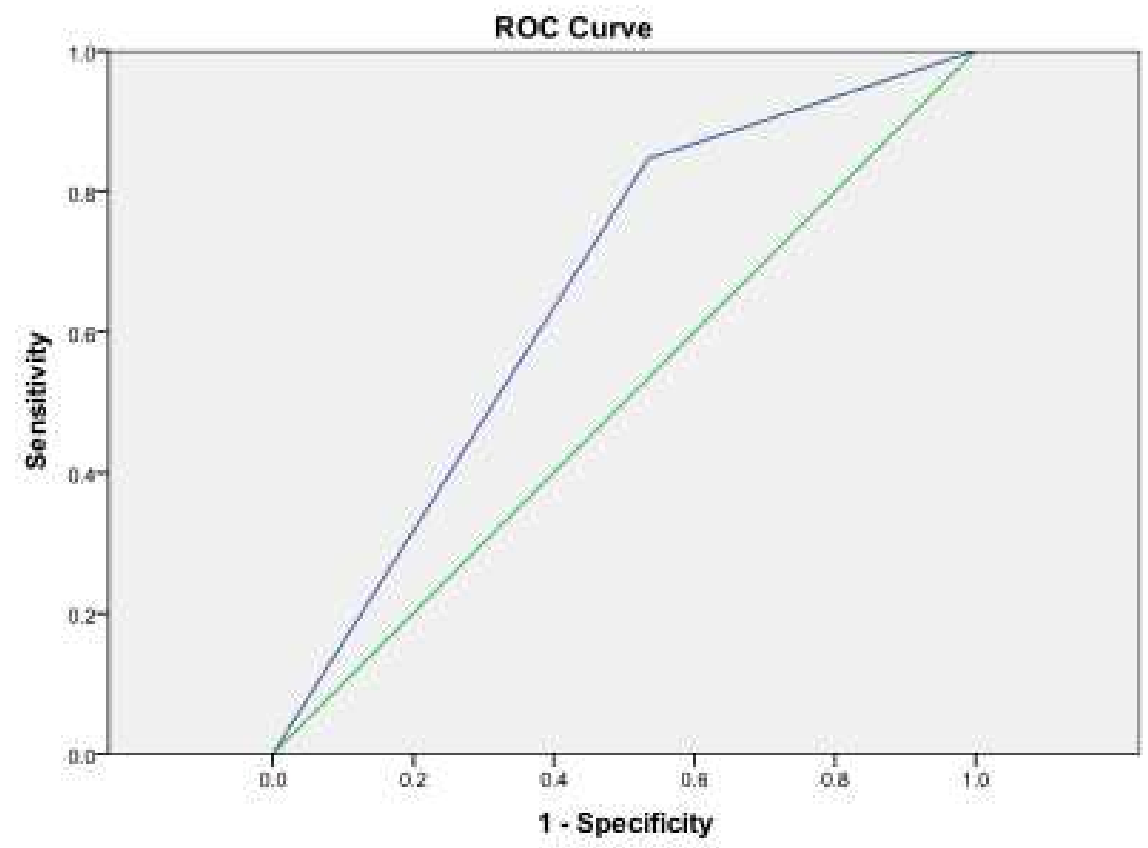

Dagonal segments are produced by ties. 
Hasan Al- Dahamsheh, Suspected appendicitis during pregnancy: prevalence and management

Histopathology confirmed appendicitis were found in 19 patients $(67.9 \%)$. Five patients had complicated appendicitis and 14 patients had simple appendicitis. The mean period of hospitalization was significantly highest in patients with perforated appendix (6.6 \pm $1.1, \mathrm{p}=.001)$ in relationship with those with normal appendix. However there is no significant differences in relationship with simple appendix ( $\mathrm{p}=.2)$.Overall 6 $(21.4 \%)$ patients experienced unfavorable fetal outcome, 4 cases of premature deliveries(one at 27 weeks died later on and three alive at 32,34 and 31 week) and 3 cases of abortions table 3 .

Table 3: Comparison of perinatal outcome and maternal morbidity in relation to Histopathological findings of appendix

\begin{tabular}{lcccccc}
\hline Complications & $\begin{array}{c}\text { Complex } \\
\text { appendix } \\
(\mathrm{n}=5)\end{array}$ & $\begin{array}{c}\text { Simple } \\
\text { appendix } \\
(\mathrm{n}=14)\end{array}$ & $\begin{array}{c}\text { Normal } \\
\text { appendix } \\
(\mathrm{n}=9)\end{array}$ & $\begin{array}{c}\text { Significance Pvalue } \\
\text { complicated vs. Simple C } \\
\text { complicated vs. Simple } \\
\text { Simple vs. Normal }\end{array}$ \\
\hline Total hospital days stay (mean \pm SD) & $6.6 \pm 1.1$ & $5.1 \pm 1$ & $4.3 \pm 0.9$ & .001 & 0.27 & 0.02 \\
Postoperative fever & $4(66.7 \%)$ & $2(15.4 \%)$ & $1(14.3 \%)$ & .03 & .02 & .96 \\
Readmission & $2(33.3 \%)$ & $2(15.4 \%)$ & $1(11.1 \%)$ & .54 & .45 & .96 \\
Premature labor pain & $2(33.3 \%)$ & $1(7.7 \%)$ & $2(22.2 \%)$ & .81 & .31 & .61 \\
Wound infection & $2(33.3 \%)$ & $2(15.4 \%)$ & $1(11.1 \%)$ & .54 & .45 & .96 \\
Abortion & 0 & $1(7.7 \%)$ & $2(22.2 \%)$ & .82 & .30 & .47 \\
Preterm delivery & $2(33.3 \%)$ & $1(7.7 \%)$ & $3(33.3 \%)$ & .34 & .28 & 1 \\
\hline
\end{tabular}

The most common final diagnosis in cases of normal appendix were premature labor pain and threatened abortion table 4.

Table 4. Final Diagnosis in the nine cases with confirmed normal appendix

\begin{tabular}{ll}
\hline Diagnosis & N \\
\hline Threatened abortion & 2 \\
Preterm labor & 2 \\
Chorioamnionitis & 2 \\
Degenerating uterine fibroid & 1 \\
Mesenteric adenitis & 2 \\
\hline
\end{tabular}


Journal of College of Medical Sciences-Nepal, 2012, Vol-8, No-1

\section{Discussion}

The incidence of suspected appendicitis among pregnant women in our hospital during the study period was 0.39 which is slightly high in comparison with other studies ${ }^{1,2,3,4}$. Early marriage and repeated pregnancies till menopause make the probability of an acute appendicitis related symptoms occurring in pregnancy higher. Previous studies have reported a variety of its frequencies throughout the pregnancy; some have shown no difference ${ }^{3}$, while the others have reported that it is more frequent during the first or second trimesters ${ }^{9,10,11,12,13}$. In this series, the frequency (38\%) of appendicitis was higher in the third trimester but not considerable

As seen in Table 1 the commonest symptoms of acute appendicitis during pregnancy were abdominal pain, nausea and vomiting, and anorexia.The signs were tachycardia, fever, tenderness and positive rebound at Rt iliac fossa. A few of these cardinal features occur normally in pregnancy and they are blunted by the anatomical and physiological changes of pregnancy. This clinical doubt makes surgeons keep waiting confirmatory signs or operate and agree to the possibility of a negative laparotomy. The incidence of negative laparotomies in our study was $32.1 \%$, which situated within the range that has been reported by other studies ${ }^{11,14,15}$. In our series the most constant symptoms with confirmed appendicitis were a history of periumbilical pain and anorexia. These findings were consistent with reports in others studies ${ }^{14,15}$. Nausea, vomiting and other locations of abdominal pain were also a complaint of patients with normal findings.

Some authors have reported that physical examination on presentation is the most reliable diagnostic tool for appendicitis and may reveal fever, increased pulse rate, rebound tenderness and guarding ${ }^{4,12}$. In our study, we found that the most important signs were tachycardia, Rt iliac Fossa tenderness, negative rebound tenderness and positive rebound tenderness. However, we found that rigidity, absence of felt mass and tenderness of other locations than RT iliac fossa were in common with patients operated for normal appendix table 2 .

The most helpful laboratory findings has been the presence of leukocytosis; it being sensitive but not specific. However, physiological leukocytosis in pregnancy makes interpretation of leukocytosis difficult ${ }^{11,14,16}$. In our study, we found that the presence of leukocytosis is of limited value for diagnosing of appendicitis figure 1.

There were conflicting reports about diagnostic accuracy of ultrasound during pregnancy for appendicitis, particularly in $3^{\text {rd }}$ trimester. While studies ${ }^{17}$ confirm that its of diagnostic value and others does $\operatorname{not}^{18,19}$. In our series, positive ultrasonic findings were of diagnostic value( sensitivity $78.9 \%$ and specificity $66.7 \%$ ) figure 2.However, the diagnosis cannot be ruled out if it is negative.

In general any type of laparotomy during pregnancy carries a risk of premature labor of $10-15 \%$, and the risk is similar for both negative laparotomy and appendectomy for simple appendicitis ${ }^{20}$. However, perinatal morbidity and mortality increases to $35-40 \%$ when perforation occurs ${ }^{12}$.In present study, two cases of 6 perforations (all in $3^{\text {rd }}$ trimester) complicated by premature delivery at 34 and 31 week with no fetal loss. Also, we found that maternal morbidity increased considerably in cases with perforated appendix table 3. The rate of abortions and premature deliveries were higher in patients with normal appendix, which it might be the primary cause of abdominal presentation table 4 . 
Hasan Al- Dahamsheh, Suspected appendicitis during pregnancy: prevalence and management

From this study it is apparent that the diagnosis of acute appendicitis in pregnant women can be problematic. Diagnostic error still high and negative laparotomy is not without complications, careful evaluation of symptoms and signs could eliminate the rate of negative laparoscopies. Timely surgical intervention is recommended in cases of suspected appendicitis in pregnancy to avoid appendicular perforation.

\section{References}

1. R.E. Andersson, M. Lambe. Incidence of appendicitis during pregnancy. Int J Epidemiol 2001;30:1281-5.

2. Edwin Chandraharan Sabaratnam Arulkumaran. Acute abdomen and abdominal pain in pregnancy. Obstetrics, Gynaecology \& Reproductive Medicine. 2008;18:205-12.

3. V. Sivanesaratnam. The acute abdomen and the obstetrician. Baillieres Best Pract Res Clin Obstet Gynaecol.2000;14(1):89-102.

4. M. Tracey, H.S. Fletcher. Appendicitis in pregnancy. Am Surg 2000;66:555e61.

5. B. Andersen, T.F. Nielsen. Appendicitis in pregnancy: diagnosis, management and complications. Acta Obstet Gynecol Scand 1999;78:758-62.

6. P. Hée, L. Viktrup. The diagnosis of appendicitis during pregnancy and maternal and fetal outcome after appendectomy. Int J Gynaecol Obstet 1999;65:129-35.

7. Marcia L McGory et al. Negative Appendectomy in Pregnant Women Is Associated with a Substantial Risk of Fetal Loss . J Am Coll Surg 2007;205:534-40.

8. R.C.Kerem. Pregnancy outcome following nonobstetric surgical intervention. The American Journal of Surgery 190 (2005) 467-73
9. T. Ueberrueck, A. Koch, L. Meyer, et al. Ninety-four appendectomies for suspected acute appendicitis during pregnancy. World J Surg . 2004;28(5):508-11.

10. E.K. Paulson, M.F. Kalady, T.N. Pappas. Clinical practice. Suspected appendicitis. N Engl J Med 2003;348:236-42.

11. M.S.Al-Qudah, M. Amr, A. Sroujieh et al. Appendectomy in pregnancy: the experience of a university hospital. J Obstet Gynecol 1999;19(4):362-4.

12. R.A. De Santis, E.G. Lockrow. Apendectomy during pregnancy: a survey of two army medical activities. Mil Med 1999;164: 671-4.

13. Esther Chen, Abbuhl Stephanie B. Appendicitis in pregnancy. Emergency Medicine Alert 2003;10(5):37e9.

14. D.M. Melnick, W.L. Wahl, V.K. Dalton. Management of general surgical problems in the pregnant patient. Am J Surg 2004;187(2):170-80.

15. H. Hodjati, T. Kazerooni. Location of the appendix in the gravid patient: a re-evaluation of the established concept. Int J Gynecol Obstet 2003;81(3):245-7.

16. R.A. Somani, G. Kaban, G. Cuddington et al. Appendicitis in pregnancy: a rare presentation. CMAJ 2003;168(8): 1020-5.

17. K.H. Lim, S.H. Bae, G.S. Seo. Diagnosis of acute appendicitis in pregnant women: value of sonography. Am J Radiol 1992;159:539e42

18. R.I. Mazze, Kallen Bengt. Appendectomy during pregnancy: a Swedish registry study of 778 cases. Obstet Gynecol 1991;77(6):835e40

19. J.D.O. Morad, J.P. Elliott, L. Erickson. et al. Appendicitis in pregnancy: new information that contradicts longheld clinical beliefs. Am J Obstet Gynecol 2000;182(2):1027e9

20. R.A. Kazar, J.J. Roslyn. The appendix. In: Schwartz SI, Shires GT, Spencer FC, Daly JM, Fischer JE, Galloway AC, editors. Principles of Surgery. USA: McGraw-Hill; 1999;1384e94. 